\title{
An Empirical Exploration of the Perceived Effectiveness of a 'Flipped Classroom' in a Business Communication Course
}

\author{
Andrea Pérez \\ University of Cantabria \\ perezran@unican.es \\ Jesús Collado \\ University of Cantabria \\ colladoj@,unican.es \\ Ángel Herrero \\ University of Cantabria \\ herreroa@unican.es \\ Héctor San Martín \\ University of Cantabria \\ smartinh@,unican.es
}

María del Mar García de los Salmones
University of Cantabria
gsalmonm@,unican.es

\begin{abstract}
This paper explores a causal model, using Structural Equation Modelling (SEM), in order to understand how the perceived effectiveness of the 'flipped classroom' and students' satisfaction with this technique can be affected by students' engagement in the 'flipped classroom' activities as well as the complexity and task orientation of such activities. The findings of the study confirm that the perceived effectiveness of the 'flipped classroom' can be calculated by its contribution to the improvement of students' general skills, knowledge and learning motivation. Students' engagement in the 'flipped classroom' activities is the key factor influencing perceived effectiveness and students' satisfaction, while the complexity and task orientation of the 'flipped classroom' also play a role in determining perceived effectiveness and satisfaction, although indirect and always mediated by engagement.
\end{abstract}

Keywords: Flipped classroom, learning effectiveness, engagement, complexity, task orientation

The introduction of teaching innovations promotes improvements in the classroom experience and the academic performance of students. This idea is especially defended in university contexts, where scholars have reported better learning outcomes and improved student satisfaction when innovative teaching methods (e.g., technology-mediated classes) are incorporated to the learning process (Lee, 2011; Hu \& Hui, 2012).

Following this line of thought, in recent years, many professors and researchers have begun to study the 'flipped classroom' as a teaching innovation with clear potential to enhance the learning experience of university students (Strayer, 2012; Toqeer, 2013; Butt, 2014; Mok, 2014; FindlayThompson \& Mombourquette, 2014; Prashar, 2015). The premise of the 'flipped classroom' technique, also sometimes referred to as 'inverted classroom', is to 'flip' the traditional sequence of activities developed in more conventional teaching models that are primarily instructor-centered. 
More precisely, in a traditional instructor-centered classroom, the teacher delivers lectures during class time and gives students homework to be done after class. In a 'flipped classroom' things are done the other way round: The teacher delivers lectures before class in the form of different types of materials, and spends class time engaging students in learning activities that involve collaboration and interaction among students (Butt, 2014; Hoffman, 2014). In recent years, scholars have reported that the use of this technique provides greater flexibility in teaching, improves student attitudes towards learning and reduces student stress and failure rates, thus accounting for better learning outcomes (Mok, 2014). Therefore, the 'flipped classroom' has started to be applied in many educational fields such as business, humanities or health and medicine, among others.

Along this line, most discussions of the 'flipped classroom' technique are focused on theoretically defending the benefits of the technique (Toqeer, 2013; Kovach, 2014) or describing a robust methodology to conduct such activities effectively in the classroom (Mok, 2014; Hoffman, 2014). However, there are still few studies that have explored what students think of the 'flipped classroom' technique and whether they perceive it as useful, effective and satisfactory in university teaching. More precisely, do students feel more satisfied when the 'flipped classroom' activities are implemented? Do perceived learning outcomes exclusively depend on the application of this new teaching technique? Alternatively, are there also other cognitive variables that contribute to the perceived effectiveness and students' satisfaction in a 'flipped classroom'? In this regard, knowing students' opinions concerning the 'flipped classroom' technique would be especially interesting for teachers and educational institutions because students' satisfaction is directly related to the effort they put in their studies and, as a consequence, their success and learning rates.

Based on engagement theory (Kearsley \& Shneiderman, 1998), the Technology Acceptance Model (TAM) (Davis, 1989) and service quality theory (Grönroos, 1984), in this paper the authors explore students' perceptions of the effectiveness and satisfaction with the 'flipped classroom' and they relate them to student engagement in the flipped activities, the complexity of the technique and the orientation of the tasks assigned to students. The application of these three theories to the study of teaching innovations suggests that simply exposing the student to a particular set of new activities may or may not work (Astin, 1984). First, engagement theory suggests that teaching must elicit sufficient student effort and investment of energy to bring about the desired learning and satisfaction outcomes. Additionally, the TAM proposes that the effectiveness of an innovation is directly affected by how effectively the pedagogical innovation functioned in terms of its ease of use; that is, the technique effectiveness is inversely correlated to the complexity of the technique (Meso \& Liegle, 2005). Thirdly, scholars have also based on marketing theories, such as the service quality theory, to corroborate that students' perceptions of the teacher's way of lecturing and the assurance about his/her competence and knowledge are the most important dimensions of educational quality that impact perceived effectiveness and students' satisfaction (Duque 2014). As suggested by Fraser and Treagust (1986), these issues are represented in the extent to which class activities are clear and well organized (i.e., task orientation).

To explore these ideas, the authors first test the perceived effectiveness of the 'flipped classroom' by evaluating how the application of this technique contributes to improve students' a) general skills (critical thinking, synthesis, etc), b) knowledge about the course content and c) learning motivation. Subsequently, the perceived effectiveness of the 'flipped classroom' is related to students' engagement, task complexity and task orientation and satisfaction.

The study is implemented with data collected from 150 students who were enrolled in a business communication course taught in the third year of the Bachelor in Business Administration at a Spanish university. Although this research context may look too narrow and interdisciplinary concerns cannot be evaluated based on the scope and size of the surveyed sample, the authors believe that the findings reported in this paper may still represent an interesting initial step to

Journal of the Scholarship of Teaching and Learning, Vol. 19, No. 2, March 2019.

josotl.indiana.edu 
advance the academic knowledge on students' self-reported perceptions of and satisfaction with the 'flipped classroom' activities.

The rest of the paper is organized as follows. In the second section, the literature review and the hypotheses are presented. The third section summarizes the methodology used to conduct the study, paying particular attention to the explanation of the 'flipped classroom' activities developed in the course, the sample collection and the measurement scales. Afterwards, the research findings are presented, differentiating between the study of the reliability and validity of the measurement scales and the test of the research hypotheses. In the fifth section, the conclusions are discussed and the authors present the limitations and future lines of research derived from the study.

\section{Literature review and hypotheses development}

\section{Perceived effectiveness of the 'flipped classroom'}

The lecture model has traditionally dominated higher education. Despite the revolution caused by the Internet in terms of interactivity and flexibility for teachers and students, still tradition dictates and most universities continue reserving several hours a week for lectures (Butt, 2014). However, scholars have recently suggested that perhaps the lecture model might not be the most effective approach for student learning because, when compared to innovative methods, students in traditional classes feel much less excited and engaged in learning (Butt, 2014).

The 'flipped classroom' technique was proposed and popularized in the early twenty-first century by Baker (2000) and Lage et al. (2000) with the aim of improving the effectiveness of classroom teaching in higher education. Simply put, this methodology flips the delivery of materials and theoretical content outside in-class hours, usually before actual teaching, to use these classes in conducting interactive and collaborative activities that deepen on the key concepts of the course and that support student active learning (Butt, 2014). In a 'flipped classroom' the teacher is moved from the center of the process to a margin, acting as technical support for student work instead of a transmitter of knowledge, as it normally happens in lectures (Hoffman, 2014). In this technique, the transmitters of knowledge are the students themselves, who explain theoretical content to their classmates within small workgroups or in activities involving the whole class (Toqeer, 2013; FindlayThompson \& Mombourquette, 2014).

Two things are critical for a 'flipped classroom' to work: (1) students are physically in the classroom when the 'flipped classroom' activities are implemented, and (2) students have read, watched and prepared the materials provided by the teacher before the session takes place (Mok, 2014). To students, the syllabus and teaching material in a 'flipped classroom' may not look particularly different to those in more traditional models, but the way of accessing these materials is different (Butt, 2014). As such, the 'flipped classroom' could be seen as a stepping stone to less structured and inquiry-based learning environments such as lectures (Hmelo-Silver, 2004).

The little academic research on the 'flipped classroom' that has been developed to date indicates that the general opinion of students about this teaching innovation is usually positive (Butt, 2014; Prashar, 2015). For example, Lage et al. (2000), Gannod et al. (2008) and Schullery et al. (2011) find favorable impressions of their students in introductory microeconomics, software engineering and business courses. Additionally, Strayer (2012) finds that students in a 'flipped classroom' become more open to co-operation and innovation as the semester progress.

Nonetheless, previous findings suggest that the mere participation of students in an innovative activity is no guarantee of success of the teaching technique (Astin, 1984; Orús et al., 2014). Instead, teachers have to place special emphasis on ensuring that the development of the activity is productive and attractive to students (Prashar, 2015). On the contrary, the mere

Journal of the Scholarship of Teaching and Learning, Vol. 19, No. 2, March 2019.

josotl.indiana.edu 
imposition of new activities, unknown to the student and involving an additional workload without a clear performance in terms of learning, could even prove counterproductive to the progress of teaching and students' perceptions. As suggested by Prashar $(2015,132)$, 'there is a pressing need to reform the traditional didactical methods to make learning both enjoyable and effective. In that direction, Bloom's revised taxonomy emphasizes collective creation. Further, the flipped classroom approach shifts the lower levels of taxonomy outside the class using interactive technologies, enabling instructors to spend more class time at the upper end of the taxonomy, with tasks that stimulate students to apply, analyze, evaluate, and create'.

These ideas refer to the perceived effectiveness of the pedagogical technique as a key construct to understand the success of teaching innovations (Alavi, 1994; Leidner \& Fuller, 1997). Effectiveness refers to the changes in skills, knowledge and attitude of the students after the completion of an activity or course (Lee, 2011). As suggested by Alavi (1994), this construct is defined in terms of self-reported learning and evaluation of classroom experience. Specifically, learning scales developed by Alavi (1994) to measure the effectiveness of collaborative learning include three dimensions referred to perceived skill development, self-reported understanding of basic knowledge and learning motivation during in-class time.

Based on these ideas, the first goal of the paper is to evaluate the effectiveness of the 'flipped classroom' technique as perceived by university students in a business communication course. Specifically, the authors suggest that perceived effectiveness of the 'flipped classroom' is achieved when the activities (a) allow students to work and develop their general skills; (b) contribute to the internalization of the key concepts of the course and (c) make class attendance more engaging, attractive and motivating for students. Thus, the first hypothesis suggests that:

H1: The perceived effectiveness of a 'flipped classroom' is composed of three dimensions related to the improvement in students' (a) general skills, (b) knowledge and (c) learning motivation.

\section{Perceived effectiveness and satisfaction}

Once the innovative technique has proved effective, then satisfaction with the technique is guaranteed (Duque, 2014). Satisfaction refers to the feelings and attitudes of students towards learning activities (Lee, 2011). Feeling happy or having a positive attitude means satisfaction. Instead, feeling unhappy or having a negative attitude means dissatisfaction (Lee, 2011). Scholars have traditionally considered that learning satisfaction is one of the major items to measure learning achievement and many have highlighted that this should be one of the main goals that higher education pursued (Appleton-Knapp \& Krentler, 2006). According to this suggestion, the second goal of the paper is to propose and test a causal model that assist teachers in understanding how they can improve their teaching effectiveness and the satisfaction of their students when using the 'flipped classroom' technique.

To explain the relationship between perceived learning effectiveness and student satisfaction, scholars frequently understand education as a service context and they build their arguments on the traditional service literature. Specifically, scholars liken perceived learning effectiveness to perceived service quality (Appleton-Knapp \& Krentler, 2006; Duque, 2014). Perceived service quality is defined as the consumer's overall impression of the relative inferiority/superiority of the organization and its services (Bitner \& Hubbert, 1994). Additionally, satisfaction is the consumer's general dis/satisfaction with the organization based on all encounters and experiences with that particular organization (Bitner \& Hubbert, 1994). In the context of higher education, this definition represents a cumulative approach that assesses the complete student experience. Thus, overall

Journal of the Scholarship of Teaching and Learning, Vol. 19, No. 2, March 2019.

josotl.indiana.edu 
student satisfaction is based on the students' general experience of the course performance, which positions perceived effectiveness as a direct antecedent of student satisfaction (Duque 2014). As Appleton-Knapp and Krentler (2006) also describe that student's perceptions of the course performance are the clearest elements determining satisfaction. Thus, the authors propose the following hypothesis:

\section{H2: The perceived effectiveness of a 'flipped classroom' has a significant and positive effect on students' satisfaction with this technique.}

\section{Engagement}

In order to improve learning and satisfaction outcomes, scholars have given a special relevance to student engagement in learning activities (Astin, 1984; Pike et al., 2012; Hu \& Hui, 2012; Hsieh, 2014). Student engagement refers to the amount of physical and psychological energy that the student devotes to the academic experience (Astin, 1984). A highly involved student is one who, for example, devotes considerable energy to studying and interacts frequently with colleagues and teachers during in-class and out-class hours (Hsieh, 2014). Conversely, a typical uninvolved student neglects studies, spends little time on campus, abstains form interaction with classmates and has infrequent contact with faculty members (Hsieh, 2014).

As reported by Kearsley and Shneiderman (1998), the engagement theory provides an adequate theoretical framework to understand the role of student engagement in the achievement of positive learning outcomes. This theory emphasizes active participation of the student in the learning process and suggests that learning will be greatest when the learning environment is structured to encourage active participation by the student (Astin, 1984; Kuh et al., 2005). Two key principles of this theory state that: '(1) The amount of student learning and personal development associated with any educational program is directly proportional to the quality and quantity of student involvement in that program and (2) the effectiveness of any educational policy or practice is directly related to the capacity of that policy or practice to increase student involvement' (Astin, 1984, 519). This theory is closely related to the experiential learning theory proposed by Kolb et al. (1990), who suggests that people learn by doing; that is, by engaging in learning activities, students internalize what they learn and can absorb and reflect on the learning experience (Hu \& Hui, 2012). By deeply engaging in learning, students undertake more effort to meet the learning requirements and accomplish the learning goal by acquiring focal knowledge or skills (Robinson \& Hullinge, 2008).

These ideas have been empirically supported by the findings of Astin (1984), Pike et al. (2012), Hu and Hui (2012) and Duque (2014). For example, Astin (1984) demonstrates that being academically involved is strongly related to satisfaction with most aspects of college life, including satisfaction with teaching methods. Thus, students who put more effort and energy into their academic experience obtain better learning and better personal development. Similarly, Duque (2014) finds that student engagement is as important as perceived service quality in explaining students' cognitive learning outcomes, which in turn explain a high percentage of satisfaction and affective learning outcomes. Hu and Hui $(2012,783)$ state that 'whether a particular learning medium improves or hinders students' learning effectiveness and satisfaction may depend on how that medium engages students in (designed) learning activities. (...) The combined results of several studies suggest that learning engagement is an important mediator for determining learning outcomes'. Based on these ideas, two new research hypotheses suggest that:

Journal of the Scholarship of Teaching and Learning, Vol. 19, No. 2, March 2019.

josotl.indiana.edu 
Pérez, Collado, Salmones, Herrero, and Martín

H3: Students' engagement in the 'flipped classroom' activities has a significant and positive effect on the perceived effectiveness of a 'flipped classroom'.

H4: Students' engagement in the 'flipped classroom' activities has a significant and positive effect on students' satisfaction with this technique.

Complexity

Additionally, the TAM (Davis, 1989) provides theory with the relevant construct of ease-of-use (vs. complexity, in its negative form) that should never be omitted when exploring students' acceptance of teaching innovations (Arbaugh, 2000; Meso \& Liegle, 2005; Lin \& Chen, 2013; Kumar et al., 2014). Although the TAM is a leading model used to explain adoption of Information Technology (IT) by people in business, industry and educational contexts (Meso \& Liegle, 2005), in the present paper the authors extend the application of this theory to a broader context of teaching innovation that does not consider IT but the 'flipped classroom' as the pedagogical innovation to be explored.

The TAM states that the factors that propel the diffusion of an innovation are its ease-of-use (vs. complexity) and its usefulness. Within the context of a university course, students are expected to feel attracted to that teaching techniques that are easy to follow and directly relevant to the course requirement tasks that they must complete (Meso \& Liegle, 2005). Specifically, beliefs that a new teaching technique is useful and easy to use influence the students' attitudes toward the technique and thereby their decision to engage in the activities assigned by the teacher (Arbaugh, 2000). While usefulness is already inherent in the perceived effectiveness of the 'flipped classroom' previously discussed in the paper, ease-of-use/complexity is yet to be included in the research of the 'flipped classroom'.

Specifically, a teaching technique is easy to use if it provides intuitive-like features that include cues or similar artifacts to guide the student through well-established procedures of converting teaching materials into coherent knowledge. Such an easy-to-use technique simplifies the learning procedure by allowing the student to focus on the content of the course, rather than on how to operate the technique. On the contrary, the complexity of the 'flipped classroom' may mitigate the students' ability to grasp and understand the core body of knowledge being disseminated in the course. Complexity also relates to emotional exhaustion (Duque, 2014) that reflects feelings of fatigue, frustration, burnout, and discontent with studies (Schaufeli et al., 2002). The complexity of a teaching innovation can generate negative thoughts and anxiety regarding students' capabilities, which can further lower perceptions and generate more anxiety, thus reinforcing the probability of inadequate performance (Bresó et al., 2011).

Thus, according to pedagogical research, effective teaching tools enhance the learning capability of students and make the mastery of difficult principles simpler (Janicki \& Liegle, 2001). Research points out that the teaching tools that prove to be more effective in most cases are those that: (1) are easy to learn, (2) map a clear and direct path from the problem to its correct solution, allow for hand-on-learning or learning-by-doing rather than passive learning such as demonstrations by the teacher, and (3) minimize the technical barriers between students and the core knowledge being disseminated in the course (Meso \& Liegle, 2005).

According to these ideas, it is expected that students' engagement in the 'flipped classroom' activities as well as the perceived effectiveness and satisfaction with this technique will be affected directly and negatively by the degree of complexity that students perceive in the 'flipped classroom' activities. This suggestion derives into three new research hypotheses:

H5: The complexity of the 'flipped classroom' activities has a significant and negative effect on students' engagement in the 'flipped classroom' activities.

Journal of the Scholarship of Teaching and Learning, Vol. 19, No. 2, March 2019.

josotl.indiana.edu 
H6: The complexity of the 'flipped classroom' activities has a significant and negative effect on the perceived effectiveness of a 'flipped classroom'.

H7: The complexity of the 'flipped classroom' activities has a significant and negative effect on students' satisfaction with this technique.

\section{Task orientation}

Finally, the authors also base their theoretical model on the service quality theory (Grönroos, 1984) to propose that task orientation is a key and direct antecedent of student engagement, perceived effectiveness and satisfaction. Task orientation refers to the extent to which teachers provide students with class activities that are clear and well organized (Fraser \& Treagust, 1986). Lin and Chen (2013) relate task orientation to pedagogical/educational quality, in the sense that the achievability and practicability of a good task orientation (i.e., answering the what, how and when questions) leads to forming pedagogical/educational quality. Consequently, these scholars apply the TAM principles to suggest that task orientation is a direct antecedent of perceived learning usefulness when it comes to use of e-learning techniques. Along this line, the application of the service quality theory to the context of higher education (Stodnick \& Rogers, 2008; Duque, 2014) suggests that the most important dimensions of quality that impact learning and satisfaction outcomes are reliability on the teacher's way of lecturing, assurance about the teacher's competence and knowledge, and the empathy of the teacher. The service quality theory proposes that this educational quality affects students' perceived learning and satisfaction directly and positively.

Along this line, previous literature suggests that teachers play a major role in students' learning in virtually any environment. For example, Lee et al. (2007) empirically confirm that the value of the learning perceived by students is positively influenced by the organization/clarity of teaching assignments. Specifically, in the research of Lee et al. (2007) student satisfaction is defined by students' attitude towards teachers, courses, instruction method and e-learning technology. Similarly, Duque (2014) corroborates that perceptions of educational quality also influence perceived cognitive learning outcomes directly and positively. Subsequently, course and instruction organization/clarity would have direct influences upon satisfaction too. Based on these ideas, the last three hypotheses of the paper are proposed:

H8: The orientation of the 'flipped classroom' activities has a significant and positive effect on students' engagement in the 'flipped classroom' activities.

H9: The orientation of the 'flipped classroom' activities has a significant and positive effect on the perceived effectiveness of a 'flipped classroom'.

H10: The orientation of the 'flipped classroom' activities has a significant and positive effect on students' satisfaction with this technique.

Figure 1 shows the conceptual model that is proposed and tested in this paper.

Journal of the Scholarship of Teaching and Learning, Vol. 19, No. 2, March 2019.

josotl.indiana.edu 


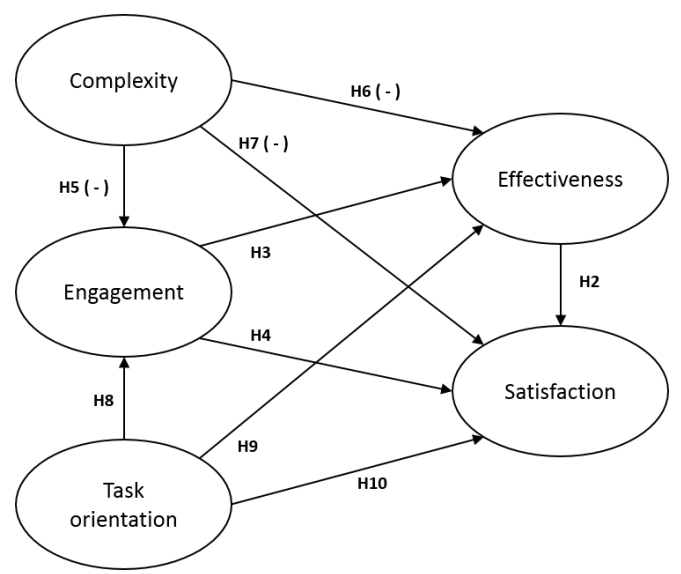

Figure 1. Conceptual model.

\section{Method}

The hypotheses test was carried out through an empirical research based on surveys among students enrolled in a business communication course taught in the third year of the Bachelor in Business Administration at a Spanish university. The authors chose this course due to its mandatory character that assured a large sample to implement Structural Equation Modeling (SEM) to test the conceptual model. This course represented six European Credit Transfer and Accumulation System (ECTS) credits, with an allocation of 63 hours of classroom activities and 87 hours of autonomous study and out-of-class activities (150 total hours). The evaluation method was divided into three parts: (1) two midterm exams; (2) a team project (delivered at the end of the semester); and (3) five in-class activities, based on the 'flipped classroom' technique and distributed among the lessons 1, 4, 5, 6 and 8 of the course. The 'flipped classroom' sessions had a total duration of 10 hours that represented $15 \%$ of the total hours of classroom activities. According to this percentage, the 'flipped classroom' activities accounted for $15 \%$ of the final grade of students. Additionally, midterm exams represented $50 \%$ of the final grade while the team project accounted for $35 \%$ of the student qualification.

Traditional and innovative teaching models were combined with the aim of gradually testing the success of the 'flipped classroom' technique (instead of implementing it as the only teaching method in the course). As suggested by Prashar (2015), the 'flipped classroom' may not be appropriate as a unique pedagogical technique because students need structured learning tasks to develop interest initially. Once course foundation is built through face-to-face instruction, the 'flipped classroom' technique can be implemented to facilitate application of concepts, analysis of practical cases, and synthesis of new problem-solving frameworks through active classroom discussion (Prashar, 2015).

Along this line, an additional introductory session was also organized at the beginning of the course, where the teacher explained the 'flipped classroom' technique to students, she set the goals to be achieved and she specified the dynamics of the sessions, the materials to be used and the instructions for the development of the 'flipped classroom' activities.

The dynamics of the 'flipped' activities were organized as follows. At the beginning of the semester, students were organized into teams of five people that collaborated during the five activities. For each activity, they were assigned a concept/idea to study, related to the theoretical content that was being worked at that time on the course, and whose materials were provided through the virtual communication tool of the course with a notice of two weeks regarding the 'flipped classroom' session. Finally, the day of the 'flipped classroom' session each team had to 
explain the work developed to colleagues, explaining the assigned concept/idea and its peculiarities within the theme that was being worked in the course. After the exhibition, a round of consultation and debate was opened, where the team had to solve all the questions raised by their classmates. At the end of the session, the teacher presented a summary of the main ideas discussed that day during the session.

As an example, one of the 'flipped' activities was orientated to the study of the different types of sales promotions that companies use in the market. This activity was designed as part of the sales promotion lesson, which took part almost at the end of the semester. Two weeks before the 'flipped' session, the teacher provided several materials on sales promotion in an online course created for this purpose in the Moodle platform. Each team was assigned one type of sales promotions chosen among the following: (1) immediate price reductions, (2) coupons, (3) demos and sampling, (4) free products, (5) repurchase of products and (6) competitions. Using the materials provided by the teacher (or any other useful information found through primary or secondary data), each team had to gather information on their sales promotion technique and collect practical examples that would help better understanding of it by the rest of classmates. The day of the 'flipped' session, the team spokesperson had to explain the sales promotion technique and the examples in the classroom, in a maximum time of 10 minutes (through a PowerPoint presentation). In addition, both the spokesperson and his team had to act as teachers, answering questions that arose about the technique in a 5-10 minute discussion that opened upon completion of the team presentation. Once the debate was finished and students considered that they had enough information about the sales promotion technique, a new team would take the stage and the same procedure would start for a new sales promotion technique.

Data was collected after the students completed the last 'flipped classroom' activity of the course, in December 2014. In the 2014-2015 academic year, 223 students were enrolled in the course. Nevertheless, only 197 students participated in the 'flipped classroom' activities. The rest of students was only enrolled part-time or was studying abroad with an Erasmus grant. Out of the 197 students involved in the activities, 150 valid questionnaires were collected (response rate $=76.14 \%$ ).

Since the way that the 'flipped classroom' was implemented in this business communication course cannot be classified as a 'flipped course' in the same way that this term is typically used in academic literature (because most of the time when this technique is employed, the entire course is flipped), this consideration has significant implications for the measurement of all the constructs in the research model presented in this paper. In order for students' responses to exclusively refer to their evaluation of the 'flipped classroom' instead of intermingle other aspects such as their perceptions of regular lectures and the team project, different sections were included in the questionnaire referring to each part of the course independently (lectures, team project and the 'flipped classroom' activities). Section 1 referred to regular lectures; Section 2 referred to the team project and Section 3 referred to students' perceptions of the 'flipped classroom' activities. The surveys were completed in the classroom. Thus, the teacher had the opportunity to stress the importance of the students clearly differentiating their perceptions of each type of teaching method in order for all the students to complete the survey successfully.

Table 1 shows the scales used in this research to measure each of the variables in the conceptual model. In all cases, 7-point Likert-type scales were used, where 1 means 'strong disagreement with the statement' and 7 means 'total agreement with the statement'. A 12-item scale measured the perceived effectiveness of the 'flipped classroom' based on the improvement of three dimensions: (1) general skills (Alavi, 1994); (2) knowledge (Alavi, 1994; Leidner \& Fuller, 1997) and learning motivation (Leidner \& Fuller, 1997). All the items were taken from the papers by Alavi (1994) and Leidner and Fuller (1997). Student engagement, task orientation and satisfaction were measured with 3-item scales taken from the papers by Fraser and Treagust (1986) and Fraser et al.

Journal of the Scholarship of Teaching and Learning, Vol. 19, No. 2, March 2019.

josotl.indiana.edu 
(1986). Finally, the complexity of the 'flipped classroom' technique was evaluated by means of a 4item scale taken from Orús et al. (2014).

Table 1. Measurement scales

\begin{tabular}{|c|c|}
\hline Latent factors & Items \\
\hline Engagement & $\begin{array}{l}\text { ENG1) I put much effort into what I did in these activities; ENG2) I paid special attention to } \\
\text { what my classmates explained during these activities; ENG3) There were opportunities for me } \\
\text { to express my opinions in these activities }\end{array}$ \\
\hline \multirow[b]{2}{*}{ Complexity } & The activities carried out following the "flipped classroom" technique... \\
\hline & $\begin{array}{l}\text { COM1) required investing much time; } \underline{\mathrm{COM} 2)} \text { required too many advanced knowledge; } \\
\text { COM3) required technological resources inaccessible to me; } \underline{\mathrm{COM} 4)} \text { had little impact on the } \\
\text { final grade for the course }\end{array}$ \\
\hline Task orientation & $\begin{array}{l}\text { ORI1) I knew exactly what had to be done in these activities; ORI2) Class activities were clear } \\
\text { so everyone knew what to do; ORI3) Activities in these classes were clearly and carefully } \\
\text { planned }\end{array}$ \\
\hline \multirow{4}{*}{ Effectiveness } & The activities carried out following the "flipped classroom" technique... \\
\hline & 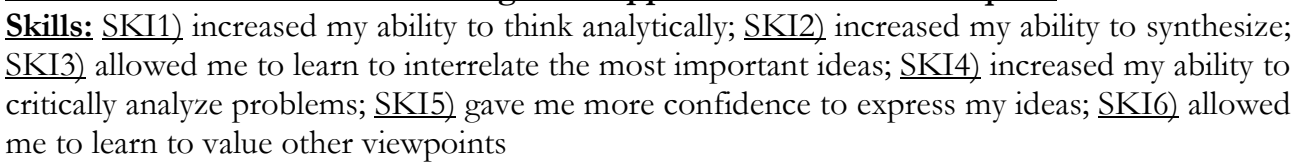 \\
\hline & 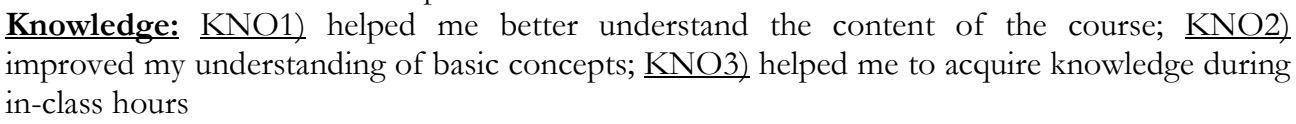 \\
\hline & $\begin{array}{l}\text { Motivation: } \\
\text { classes more entertaining; } \text { MOT3) helped me to be more attentive during classes }\end{array}$ \\
\hline Satisfaction & $\begin{array}{l}\text { SAT1) Roughly speaking, I'm satisfied with these activities; SAT2) I was always looking } \\
\text { forward to participating in these activities; } \underline{\text { SAT3) After participating in these activities, I used }} \\
\text { to have a sense of satisfaction }\end{array}$ \\
\hline
\end{tabular}

\section{Findings}

\section{Multidimensionality of the perceived effectiveness of the 'flipped classroom'}

The first research goal of the study was to corroborate the multidimensional structure of the perceived effectiveness of the 'flipped classroom' (H1). For this purpose, the authors implemented first-and second-order Confirmatory Factor Analyses (CFA) of the scale with the statistical software EQS v.6.1. The findings showed adequate values in terms of reliability, convergent validity, discriminant validity and goodness of fit (Hair et al., 2010). Thus, the multidimensionality of the scale was confirmed and the hypothesis $\mathrm{H} 1$ was supported (Tables 2 and 3).

Along this line, the findings of the second-order CFA showed that the three dimensions of the effectiveness scale loaded quite similarly to this construct $\left(0.91<\beta_{i}<0.95\right)$. Thus, the improvement in general skills, knowledge and learning motivations is a very reliable indicator to guarantee the perceived effectiveness of the 'flipped classroom'. The findings of this study also showed that the implementation of the 'flipped classroom' activities was especially successful in the context of the present research. As it is shown in Table 2, out of the three dimensions composing perceived effectiveness, the 'flipped classroom' was especially effective in terms of improving students' learning motivation (Mean=5.66, s.d=1.27), although effects were also very positive in terms of knowledge generation (Mean=5.52, s.d=1.11) and acquisition of general skills (Mean=5.34, s.d $=0.88)$. 
Table 2. First-order confirmatory factor analysis of the "effectiveness" scale

\begin{tabular}{|c|c|c|c|c|c|c|c|}
\hline Latent factors & Mean & s.d & Items & $\beta *$ & $\mathbf{R}^{2}$ & Cronbach $\alpha$ & AVE \\
\hline Skills & 5.34 & 0.88 & $\begin{array}{l}\text { SKI1 } \\
\text { SKI2 } \\
\text { SKI3 } \\
\text { SKI4 } \\
\text { SKI5 } \\
\text { SKI6 }\end{array}$ & $\begin{array}{l}0.83 \\
0.76 \\
0.81 \\
0.80 \\
0.71 \\
0.72\end{array}$ & $\begin{array}{l}0.69 \\
0.58 \\
0.66 \\
0.65 \\
0.51 \\
0.51\end{array}$ & 0.90 & 0.60 \\
\hline Knowledge & 5.52 & 1.11 & $\begin{array}{l}\mathrm{KNO} 1 \\
\mathrm{KNO} 2 \\
\mathrm{KNO} 3\end{array}$ & $\begin{array}{l}0.79 \\
0.81 \\
0.84\end{array}$ & $\begin{array}{l}0.63 \\
0.66 \\
0.71 \\
\end{array}$ & 0.86 & 0.66 \\
\hline Motivation & 5.66 & 1.27 & $\begin{array}{l}\text { MOT1 } \\
\text { MOT2 } \\
\text { MOT3 }\end{array}$ & $\begin{array}{l}0.92 \\
0.97 \\
0.77 \\
\end{array}$ & $\begin{array}{l}0.84 \\
0.93 \\
0.59 \\
\end{array}$ & 0.92 & 0.79 \\
\hline \multicolumn{8}{|c|}{ "Discriminant validity** } \\
\hline $\begin{array}{l}\text { Skills } \\
\text { Knowledge } \\
\text { Motivation }\end{array}$ & & & $\begin{array}{r} \\
.79-0.95] \\
.69-0.86]\end{array}$ & & $\begin{array}{r}0.87(0.04) \\
- \\
{[0.69-0.90]}\end{array}$ & & $\begin{array}{r}0.78(0.04) \\
0.80(0.05) \\
-\end{array}$ \\
\hline
\end{tabular}

Table 3. Second-order confirmatory factor analysis of the "effectiveness" scale

\begin{tabular}{lcrr}
\hline \hline Latent factors & Dimensions & $\beta$ & t-test \\
\hline \hline & Skills & 0.92 & $8.92^{*}$ \\
Effectiveness & Knowledge & 0.95 & $8.15^{*}$ \\
& Motivation & 0.91 & $7.24^{*}$ \\
\hline \hline
\end{tabular}

$* \mathrm{p}<0.05 ;$ Goodness of fit: $\mathrm{S}-\mathrm{B} \chi^{2}(\mathrm{df})=51.77(49), \mathrm{p}=0.37 ; \mathrm{NFI}=0.92 ; \mathrm{NNFI}=0.99 ; \mathrm{CFI}=0.99 ; \mathrm{IFI}=0.99 ; \mathrm{RMSEA}=0.02$

\section{Causal relationships}

The second research goal of the study was to explore the role of student engagement, complexity of the 'flipped classroom' technique and task orientation as direct antecedents of the perceived effectiveness and students' satisfaction (H2 to H10). For this purpose, the authors first tested the reliability, convergent validity, discriminant validity and goodness of fit of all the scales in the analysis by means of a new first-order CFA. In all the cases, the findings showed satisfactory values (Table 4). The descriptive statistics show that students' perceptions of the task orientation (Mean=5.35, s.d=1.19) and effectiveness (Mean=5.46, s.d=0.95) of the 'flipped classroom' activities as well as their own engagement (Mean=5.33, s.d=0.92) and satisfaction (Mean=5.15, s.d=1.24) with the 'flipped classroom' were very positive, while the technique was not perceived as especially complex in terms of its usability (Mean=3.93, s.d=1.30). 
Table 4. First-order confirmatory factor analysis of the causal model

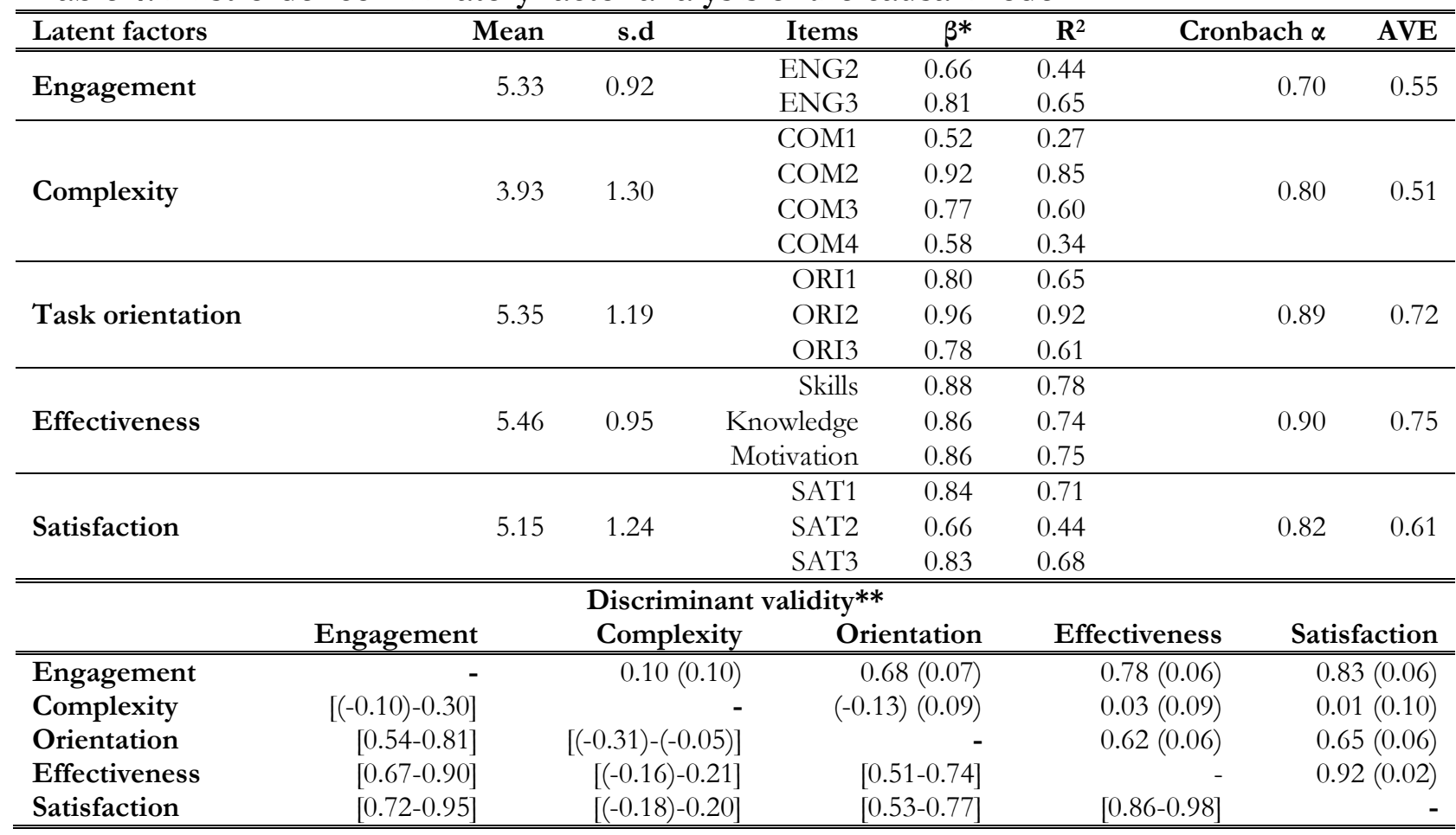

$* \mathrm{p}<0.05$; Goodness of fit: S-B $\chi^{2}(\mathrm{df})=104.31(80), \mathrm{p}=0.04 ; \mathrm{NFI}=0.88 ; \mathrm{NNFI}=0.96 ; \mathrm{CFI}=0.97$; IFI=0.97; RMSEA=0.05

** The figures over the diagonal indicate the correlation (and error) between pairs of latent factors. The figures below the diagonal represent confidence intervals.

Additionally, the authors implemented a Structural Equation Model (SEM) with the statistical software EQS v.6.1 to test the value and significance of the nine relationships proposed in the causal model. As it is shown in Table 5, the findings indicated that the causal model fitted the sample well (Hair et al., 2010).

As to the results found (Table 5; Figure 2), the perception that students had of the 'flipped classroom' effectiveness had a positive and significant effect on the improvement of students' satisfaction with this technique $(\beta=0.68, \mathrm{p}<0.05)$. Thus, the findings of this research support the hypothesis H2. Students' engagement in the 'flipped classroom' activities also had direct and positive influences on perceived effectiveness $(\beta=0.68, \mathrm{p}<0.05)$ and students' satisfaction $(\beta=0.35, \mathrm{p}<0.10)$. Thus, the hypotheses $\mathrm{H} 3$ and $\mathrm{H} 4$ are also supported. On the contrary, complexity was shown to only have a direct and positive impact on students' engagement $(\beta=0.18, \mathrm{p}<0.05)$, while its direct effect on perceived effectiveness $(\beta=(-0.03), \mathrm{p}>0.05)$ and satisfaction $(\beta=(-0.03), \mathrm{p}>0.05)$ was not statistically significant. These findings contradict the expectations of the authors. Thus, the hypotheses $\mathrm{H} 5, \mathrm{H} 6$ and $\mathrm{H} 7$ are not supported by the findings of this research. Task orientation also had a direct and positive effect on students' engagement $(\beta=0.69, \mathrm{p}<0.05)$. This finding supports the hypothesis H8. Finally, the findings show that the direct effects of task orientation on perceived effectiveness $(\beta=0.03, \mathrm{p}>0.05)$ and students' satisfaction $(\beta=0.16, \mathrm{p}>0.05)$ were statistically insignificant. Based on these findings, the hypotheses $\mathrm{H} 9$ and $\mathrm{H} 10$ are not supported. 
Table 5. Test of the relationships of the causal model

\begin{tabular}{llrrr}
\hline \hline Hypotheses & $\beta$ & t-test & Contrast \\
\hline \hline H2 & Effectiveness $\rightarrow$ Satisfaction & 0.68 & $3.93^{*}$ & Supported \\
\hline H3 & Engagement $\rightarrow$ Effectiveness & 0.68 & $4.81^{*}$ & Supported \\
\hline H4 & Engagement $\rightarrow$ Satisfaction & 0.35 & $1.91^{* *}$ & Supported \\
\hline H5 & Complexity $\rightarrow$ Engagement & 0.18 & $2.23^{*}$ & Not supported \\
\hline H6 & Complexity $\rightarrow$ Effectiveness & $(-0.03)$ & $(-0.36)$ & Not supported \\
\hline H7 & Complexity $\rightarrow$ Satisfaction & $(-0.03)$ & $(-0.46)$ & Not supported \\
\hline H8 & Task orientation $\rightarrow$ Engagement & 0.69 & $6.18^{*}$ & Supported \\
\hline H9 & Task orientation $\rightarrow$ Effectiveness & 0.16 & 1.22 & Not supported \\
\hline H10 & Task orientation $\rightarrow$ Satisfaction & 0.03 & 0.36 & Not supported \\
\hline \hline
\end{tabular}

$* \mathrm{p}<0.05, * * \mathrm{p}<0.10$

Goodness of fit: $\mathrm{S}-\mathrm{B} \chi^{2}(\mathrm{df})=98.33(84), \mathrm{p}=0.14 ; \mathrm{NFI}=0.89 ; \mathrm{NNFI}=0.97 ; \mathrm{CFI}=0.98 ; \mathrm{IFI}=0.98 ; \mathrm{RMSEA}=0.04$

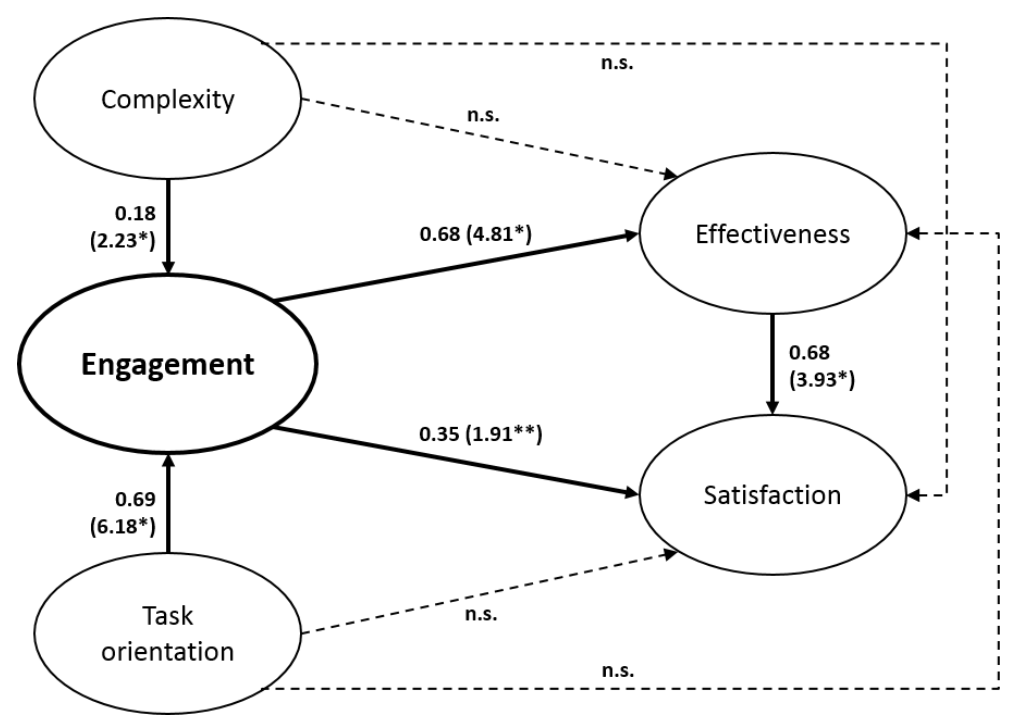

Figure 2. Findings.

\section{Conclusions, limitations and future lines of research}

In this paper, the authors have explored the 'flipped classroom' effectiveness, as it is perceived by university students enrolled in a business communication course. For this purpose, the authors have applied three educational and marketing theories that have been traditionally explored to understand the adoption of teaching innovations in higher education. The findings presented in the paper highlight that one of these theoretical approaches, engagement theory (Kearsley \& Shneiderman, 1998), is the key framework to understand the perceived effectiveness as well as students' satisfaction with the 'flipped classroom'. This theory defends the essential role of students' engagement in the development of the innovative activities in order for them to be successful. As it will be discussed in this section, most of the findings of this paper can be better understood under the light of this theory.

As a first interesting finding, the empirical exploration of students' perceptions suggest that a 'flipped classroom' is highly appreciated among university students, with scores above 5 (out of 7 ) in terms of skill development, knowledge generation and the improvement of learning motivation. 
Thus, the 'flipped classroom' is an effective teaching innovation in terms of learning outcomes in higher education. The 'flipped classroom' is especially useful for boosting students' motivation to learn and participate in classroom activities. As suggested by Çetin (2015), learning motivation is essential for the success of teaching in higher education contexts. Thus, university teachers could benefit significantly from the application of the 'flipped classroom' in order to achieve the necessary motivation of their students. It is also significant that the three dimensions of perceived effectiveness tested in this paper load significantly and very similarly to the second-order construct of perceived effectiveness. Thus, in addition to learning motivation, skill development and knowledge generation are also key features to assure the perceived effectiveness of the 'flipped classroom'.

The findings of the paper also confirm the role of students' engagement, task complexity and task orientation as significant antecedents of perceived effectiveness and students' satisfaction. Out of the three variables, engagement is presented as the key feature to understand both perceived effectiveness and satisfaction. This idea is supported by its direct effects on perceived effectiveness and satisfaction as well as the mediating role that engagement plays in the effects of complexity and task orientation on perceived effectiveness and satisfaction. These findings are explained by the engagement theory previously explored in this paper. Engagement theory suggests that students learn more by doing and highly engaging in activities because this way they can absorb more information and they internalize what they learn more strongly. By deeply engaging in class assignments, students undertake more effort to meet the teacher's requirements and accomplish the learning goal largely (Robinson \& Hullinger, 2008). Along this line, the empirical findings of the present paper align with the experimental data reported by $\mathrm{Hu}$ and Hui (2012), who demonstrate that the effects of technology-mediated learning on learning effectiveness and satisfaction are mostly mediated by learning engagement. These scholars confirm that the use of passive teaching techniques (i.e., preprogrammed video contents to deliver learning materials) negatively affects learning engagement, which in turn reduces perceived learning effectiveness and satisfaction.

The service quality theory (Grönroos, 1984) also assist the authors to understand the findings of this research, although only partially. Specifically, this theory suggests that task orientation is a crucial component of perceived service quality in educational contexts and, consequently, it plays a significant role in the perception of teaching effectiveness and students' satisfaction. In the present paper, the findings confirm the relevance of task orientation to engage students in the 'flipped classroom' activities. The correct organization of the activities derives into better perceptions of effectiveness and satisfaction too. However, these effects are only indirect and mediated by students' engagement.

On the contrary, the findings suggest that TAM is not an adequate theoretical framework to understand the 'flipped classroom'. In this regard, while the theory suggests that the complexity of a teaching innovation is negatively correlated with students' engagement, perceived effectiveness and learning satisfaction, this research demonstrates the opposite effects, in the sense that complexity increases students' engagement in the 'flipped classroom' activities and, consequently, it also has indirect and positive effects on perceived effectiveness and students' satisfaction. TAM considers that the complexity of the teaching innovation may mitigate the students' ability to grasp and understand the core body of knowledge being disseminated in the course (Meso \& Liegle, 2005). While this idea seems unquestionable, the authors of the present paper consider that a complex activity also involves investing more time in its development, while the student should also pay more attention and effort to solve the problem correctly. Thus, certain degree of complexity is desirable in order for students to devote more time and attention to the 'flipped classroom' activities. Otherwise, if the class assignment is too easy, the resolution of the problem may become routine for the 
students, demotivating them and leading to the loss of interest in solving the assigned problems in the best way possible.

The findings presented in this research have several implications for higher education teachers. First, teachers can improve the classroom environment by implementing the 'flipped classroom' activities because such activities are highly effective in terms of skill development, knowledge generation and the improvement of learning motivation. As previously suggested in literature, it may not be advisable that teachers change completely from traditional lectures to the 'flipped classroom' (Prashar, 2015). However, the gradual implementation of flipped activities in combination with traditional methods highly benefits learning outcomes and students' satisfaction. In the case of the business communication course explored in this research, only $15 \%$ of the activities were flipped during the semester. In future academic years, a gradual increase in this percentage will be assumed to take the course closer to traditional approaches to the 'flipped classroom' (i.e., 100\% flipped activities).

Nonetheless, it should also be noted that the previous findings of some scholars who have also explored teaching innovations (Orús et al., 2014) suggest that the implementation of an innovative teaching method such as the 'flipped classroom' may not be enough to guarantee its success. On the contrary, teachers have to place special emphasis on ensuring the effective development of these class activities. For this purpose, teachers should create and implement continuous methods of assessment of the acquisition of skills, knowledge and students' motivation, which are the three pillars of the perceived effectiveness of the 'flipped classroom' in higher education. By doing this, teachers should not only focus on knowledge acquisition, which used to be one of the main goals of higher education in the past. On the contrary, the new framework of the European Higher Education Area (EHEA) has turned the student into the main protagonist of the new educational scenario and point to a course design based primarily on general and specific skills and competencies, which are critical in the process of student self-learning.

Additionally, teachers also have to create inspiring activities based on features that are closely related to the students' interests and concerns. An interesting way to achieve this goal could be the proposal of brief surveys at the beginning of the semester to identify the factors that promote engagement. For instance, to improve engagement over the next academic years, a new survey will be applied at the beginning of each semester to students enrolled in the business communication course explored in this research. The goal of the survey will be to identify the main communication topics and teaching techniques that students appreciate better for their learning purposes, so that the content and teaching methods applied in the course can accommodate students' expectations better.

Along this line, the present research suggest that one key factor to improve engagement is task complexity. Accordingly, teachers should create activities with a certain degree of complexity because they improve the students' engagement in the 'flipped classroom' activities. Too simple activities become routine and do not require the students to make an extra effort, reducing their engagement and jeoparding the perceived effectiveness of the technique and students' satisfaction. Therefore, and because the 'flipped classroom' activities implemented in the business communication course explored in this research were not perceived as significantly complex by students in the sample (Mean=3.93, s.d=1.30), in future academic years the complexity of the flipped activities will be gradually increased to make them challenging enough to motivate students' engagement, improve perceive effectiveness and boost satisfaction significantly.

As for the limitations of this paper, the sample chosen stands out because it is relatively small and it does not look across multiple institutions, degrees or educational levels. In this regard, the business communication course in which the data was collected for this study was only taught in the third year of the Bachelor in Business Administration of the Spanish university chose for the study. Therefore, the authors were unable to expand the study to other research contexts as to 
compare the outcomes in different classroom environments (e.g., engineering, education, math, etc.). Nonetheless, students in diverse research contexts may show different learning approaches and, as a consequence, they may react differently to diverse learning styles. Therefore, future research should replicate the study with different samples of students, courses and degrees, to validate the perceived effectiveness of the 'flipped classroom' technique in areas other than university teaching of marketing courses. The sample size is also a limitation that can be overcome if the study is applied in a wider field of research. Additionally, the partially-flipped learning approach that was adopted in the business communication course explored in this research (i.e., only $15 \%$ of the activities in the course were actually flipped) may represent another limitation in terms of the generalization of the findings of the present study. In this regard, the fewer flipped activities a course have, the less there is that can be extrapolated by those who employ the flipped model more extensively. Finally, the study did not include moderating variables that could also have significant impacts on the perceived effectiveness of the 'flipped classroom' technique. For example, future scholars should control for the effects of multiple instructors or different student characteristics in the causal model.

\section{References}

Alavi, M. (1994). Computer-mediated collaborative learning: An empirical evaluation. MIS Quarterly, $18(2), 159-174$.

Appleton-Knapp, S.K. and Krentler, K.A. (2006). Measuring student expectations and their effects on satisfaction: The importance of managing student expectations. Journal of Marketing Education, 28 (3), 254-264.

Arbaugh, J.B. (2000). How classroom environment and student engagement affect learning in Internet-based MBA courses. Business Communication Quarterly, 63 (4), 9-26.

Astin, A.W. (1984). Student involvement: A developmental theory for higher education. Journal of College Student Personnel, 25 (4), 297-308.

Baker, J.W. (2000). The 'classroom flip': Using web course management tools to become the guide by the side. Paper presented at the 11th International Conference on College Teaching and Learning, Jacksonville, FL: April 12-15.

Bitner, M.J. and Hubbert, A.R. (1994). Encounter satisfaction versus overall satisfaction versus quality. In R.T. Rust and R.L. Oliver (Eds.), Service quality: New directions in theory and practice (72-94). Thousand Oaks, CA: SAGE Publications, Inc.

Bresó, E., Schaufeli, W.B. and Salanova, M. (2011). Can a self-efficacy based intervention decrease burnout, increase engagement, and enhance performance? A quasi experimental study. Higher Education, 61, 339-355.

Butt, A. (2014). Student views on the use of a flipped classroom approach: Evidence from Australia. Business Education \& Accreditation, 6 (1), 33-43.

Çetin, B. (2015). Academic motivation and approaches to learning in predicting college students' academic achievement: Findings from Turkish and US samples. Journal of College Teaching \& Learning, 12 (2), 141-150. 
Davis, F.D. (1989). Perceived usefulness, perceived ease of use, and user acceptance of information technology. MIS Quarterly, 13 (3), 319-340.

Duque, L.C. (2014). A framework for analysing higher education performance: Students' satisfaction, perceived learning outcomes, and dropout intentions. Total Quality Management, $25(1), 1-21$.

Findlay-Thompson, S. and Mombourquette, P. (2014). Evaluation of a flipped classroom in an undergraduate business course. Business Education \& Accreditation, 6 (1), 63-71.

Fraser, B.J. and Treagust, D.F. (1986). Validity and use of an instrument for assessing classroom psychosocial environment in higher education. Higher Education, 15 (1/2), 37-57.

Fraser, B.J., Treagust, D.F. and Dennis, N.C. (1986). Development of an instrument for assessing classroom psychosocial environment at universities and colleges. Studies in Higher Education, $11(1), 43-54$.

Gannod, G.C., Burge, J.E. and Helmick, M.T. (2008). Using the inverted classroom to teach software engineering. Paper presented at the 30th International Conference on Software Engineering, Leipzig (Germany): May 10-18.

Grönroos, C. (1984). A service quality model and its marketing implications. European Journal of Marketing, 18 (4), 36-44.

Hair, J.F., Black, W.C., Babin, B.J. and Anderson, R.E. (2010). Multivariate data analysis. Upper Saddle River, NJ: Prentice Hall.

Hmelo-Silver, C.E. (2004). Problem-based learning: What and how do students learn? Educational Psychology Review, 16 (3), 235-266.

Hoffman, E.S. (2014). Beyond the flipped classroom: Redesigning a research methods course for e3 instruction. Contemporary Issues in Education Research, 7 (1), 51-62.

Hsieh, T. (2014). Motivation matters? The relationship among different types of learning motivation, engagement behaviors and learning outcomes of undergraduate students in Taiwan. Higher Education, 68, 417-433.

Hu, P.J. and Hui, W. (2012). Examining the role of learning engagement in technology-mediated learning and its effects on learning effectiveness and satisfaction. Decision Support Systems, 53, 782-792.

Janicki, T.N. and Liegle, J.O. (2001). Development and evaluation of a framework for creating webbased learning modules. Journal of Asynchronous Learning Networks, 5 (1), 58-84.

Kearsley, G. and Shneiderman, B. (1986). Engagement theory: A framework for technology-based teaching and learning. Educational Technology, 38 (5), 20-23. 
Kovach, J.V. (2014). Leadership in the 'classroom'. The Journal for Quality and Participation, 37 (1), 39.

Kolb, D.A., Rubin, I.M. and Osland, J. (1990). Organizational behaviour: An experiential approach. Englewood Cliffs, NJ: Prentice Hall.

Kuh, G., Kinzie, J., Schuh, J. and Whitt, E. (2005). Student success in college: Creating conditions that matter. San Francisco, CA: Jossey Bass.

Kumar, S., Kumar, J. and Madhumohan, S. (2014). Students' acceptance and satisfaction of learning through course websites. Education, Business and Society: Contemporary Middle Eastern Issues, 7 (2/3), 152-166.

Lage, M.J., Platt, G.J. and Treglia, M. (2000). Inverting the classroom: A gateway to creating an inclusive learning environment. Journal of Economic Education, 31 (1), 30-43.

Lee, Y. (2011). A study on the effect of teaching innovation on learning effectiveness with learning satisfaction as a mediator. World Transactions on Engineering and Technology Education, 9 (2), 92101.

Lee, Y., Tseng, S. and Liu, F. (2007). Antecedents of learner satisfaction toward e-learning. Journal of American Academy of Business, 11 (2), 161-168.

Leidner, D.E. and Fuller, M. (1997). Improving student learning of conceptual information: Supported collaborative learning vs. individual constructive learning. Decision Support Systems, 20,149-163.

Lin, S. and Chen, S. (2013). Innovation attributes and pedagogical quality: A concretization of joint theories on course management systems acceptance. Quality \& Quantity, 47, 2309-2317.

Meso, P. and Liegle, J. (2005). An exploratory assessment of the pedagogical effectiveness of a systems development environment. Journal of Information Systems Education, 16 (2), 157-166.

Mok, H.N. (2014). Teaching tip: The flipped classroom. Journal of Information Systems Education, 25 (1), 7-11.

Oliver, R.L. (1980). A cognitive model of the antecedents and consequences of satisfaction decisions. Journal of Marketing Research, 17 (4), 460-469.

Orús, C., Barlés, M.J., Belanche, D., Casaló, L.V., Fraj, E. and Gurrea, R. (2014). Consecuencias afectivas y objetivas del uso de un canal de youtube de apoyo a la docencia en marketing. Paper presented at the annual Congreso Nacional de Marketing AEMARK, Elche (Spain): September 17-19.

Pike, G.R., Smart, J.C. and Ethington, C.A. (2012). The mediating effects of student engagement on the relationships between academic disciplines and learning outcomes: an extension of Holland's theory. Research in Higher Education, 53, 550-575. 
Prashar, A. (2015). Assessing the flipped classroom in operations management: A pilot study. Journal of Education for Business, 90, 126-138.

Robinson, C.C. and Hullinger, H. (2008). New benchmarks in higher education: Student engagement in online learning. Journal of Education for Business, 84 (2), 101-108.

Schaufeli, W.B., Martínez, I.M., Marques, A., Salanova, M. and Bakker, A.B. (2002). Burnout and engagement in university students: A cross national study. Journal of Cross Cultural Psychology, 33, 464-481.

Schullery, N.M., Reck, R.F. and Schullery, S.E. (2011). Toward solving the high enrollment, low engagement dilemma: a case study in introductory business. International Journal of Business, Humanities and Technology, 1 (2), 1-9.

Stodnick, M. and Rogers, P. (2008). Using SERVQUAL to measure the quality of the classroom experience. Decision Sciences Journal of Innovative Education, 6 (1), 115-133.

Strayer, J.F. (2012). How learning in an inverted classroom influences cooperation, innovation and task orientation. Learning Environment Research, 15 (2), 171-193.

Toqeer, R. (2013). Flipped classroom concept application to management and leadership course for maximizing the learning opportunities. The Business \& Management Review, 3 (4), 137-144. 